\title{
Implementation of secondary stroke prevention protocol for ischaemic stroke patients in primary care
}

\author{
YK Choi *, JH Han, Richard Li, Kenny Kung, Augustine Lam
}

\section{A B S T R A C T}

Objective: To investigate the effectiveness of a secondary stroke prevention protocol in the general out-patient clinic.

Design: Cohort study with pre- and postintervention comparisons.

Setting: Two general out-patient clinics in Hong Kong.

Patients: Ischaemic stroke patients who had longterm follow-up in two clinics were recruited. The patients of one clinic received the intervention (intervention group) and the patients of the second clinic did not receive the intervention (control group). The recruitment period lasted for 6 months from 1 September 2008 to 28 February 2009. The pre-intervention phase data collection started within this 6-month period. The protocol implementation started at the intervention clinic on 1 April 2009. The post-intervention phase data collection started 9 months after the protocol implementation, and ran for 6 months from 1 January 2010 to 30 June 2010.

Main outcome measures: Clinical data before and after the intervention, including blood pressure, glycated haemoglobin level, low-density lipoprotein level and prescription pattern, were compared between the two groups to see whether there was enhancement of secondary stroke management.

This article was published on 16 Jan 2015 at www.hkmj.org.
Results: A total of 328 patients were recruited into the intervention group and 249 into the control group; data of 256 and 210 patients from these groups were analysed, respectively. After intervention, there were significant reductions in mean $( \pm$ standard deviation) systolic blood pressure (135.2 $\pm 17.5 \mathrm{~mm}$ $\mathrm{Hg}$ to $127.7 \pm 12.2 \mathrm{~mm} \mathrm{Hg}$ ), glycated haemoglobin level $(7.2 \pm 1.0 \%$ to $6.5 \pm 0.8 \%)$, and low-density lipoprotein level $(3.4 \pm 0.8 \mathrm{mmol} / \mathrm{L}$ to $2.8 \pm 1.3$ $\mathrm{mmol} / \mathrm{L}$ ) in the intervention group (all $\mathrm{P}<0.01$ ). There were no significant reductions in mean systolic blood pressure, glycated haemoglobin level, or lowdensity lipoprotein level in the control group. There was a significant increase in statin use $(\mathrm{P}<0.01)$ in both clinics.

Conclusion: Through implementation of a clinic protocol, the standard of care of secondary stroke prevention for ischaemic stroke patients could be improved in a general out-patient clinic.

Hong Kong Med J 2015;21:136-42

DOI: $10.12809 / \mathrm{hkmj} 144236$

${ }^{1}$ YK Choi *, FHKCFP, FHKAM (Family Medicine)

1 JH Han, MD, PhD

${ }^{2}$ R Li, FHKCP, FHKAM (Medicine)

${ }^{3}$ K Kung, FHKCFP, FHKAM (Family Medicine)

${ }^{4}$ A Lam, FHKCFP, FHKAM (Family Medicine)

${ }^{1}$ Lek Yuen General Out-patient Clinic, Department of Family Medicine, New Territories East Cluster, Hong Kong

2 Department of Medicine, Pamela Youde Nethersole Eastern Hospital, Hong Kong

${ }^{3}$ Department of Family Medicine and Primary Care, The University of Hong Kong, Hong Kong

${ }^{4}$ Department of Family Medicine, New Territories East Cluster, Hong Kong

* Corresponding author: yuekwan@hotmail.com

\section{New knowledge added by this study \\ A standard secondary stroke prevention protocol can significantly improve the control of cardiovascular risk factors in ischaemic stroke patients. \\ - Implementation of such a programme is effective and feasible in local primary care. \\ Implications for clinical practice or policy \\ - This study supports more widespread use of a secondary stroke prevention programme in the setting of a general out-patient clinic.}

\section{Introduction}

Stroke is the second commonest cause of death worldwide ${ }^{1}$ and the fourth leading cause of death in Hong Kong. ${ }^{2}$ Stroke is also the commonest cause of permanent disability in adults. Patients with stroke are at high risk for recurrent stroke and other major vascular events. As the ageing population is increasing in most developed countries, stroke will remain a major burden to patients' families and carers, the health care system, and the community. According to local data from Hong Kong, cerebrovascular disease was the principal diagnosis for about 26500 in-patient discharges and deaths in all hospitals and accounted for $7.5 \%$ of all deaths in $2012 .^{3}$ The mortality rate was 
significantly higher in patients with stroke recurrence than in those without. ${ }^{4,5}$ Prevention of recurrent stroke offers great potential for reducing the burden of this disease.

Over $80 \%$ of all strokes are ischaemic stroke. There are effective strategies for secondary prevention of ischaemic stroke, which are summarised as follows ${ }^{6}$ :

(1) Modification of lifestyle risk factors (smoking, alcohol consumption, obesity, physical inactivity).

(2) Modification of vascular risk factors (hypertension, hypercholesterolaemia, diabetes).

(3) Antiplatelet therapy for non-cardioembolic ischaemic stroke.

(4) Anticoagulation for cardioembolic stroke.

(5) Intervention for symptomatic carotid stenosis. As stroke patients need lifelong monitoring and control of risk factors, family physicians play the most important role in providing secondary stroke prevention care. However, despite the availability of evidence-based guidelines, studies show that adherence to these preventive strategies by physicians is poor. ${ }^{7-11}$ Local Hong Kong data about secondary stroke prevention in primary care are largely lacking. This study aimed to review the clinical effectiveness of a secondary stroke prevention programme in a general out-patient clinic (GOPC).

\section{Methods}

This was a cohort study of pre- and post-intervention comparison between patients receiving or not receiving the intervention to ascertain the effect of a secondary stroke prevention programme on clinical outcomes.

\section{Clinic setting}

The Lek Yuen GOPC was selected as the intervention site where the secondary stroke prevention programme was implemented. Another clinic, the Ma On Shan GOPC, was selected as the control site, where usual care was provided. Both clinics are large public primary care clinics under the management of the Department of Family Medicine of the New Territories East Cluster of the Hospital Authority. Both clinics are accredited Family Medicine Training Centres with similar service throughput annually, covering a population of around 600000 and providing approximately 30000 attendances monthly.

Most of the stroke patients in the clinics are referred from the public hospitals. The patients usually have a history of minor stroke with good functional recovery and are clinically stable.

\section{Clinic protocol development and implementation}

A protocol of secondary stroke prevention (Box)

\section{基層醫療層面上針對缺血性中風患者而實施的二 級預防中風計劃 \\ 蔡宇均、韓璟浩、李梓強、龔敬樂、林㻧}

目的：探討普通科門診服務中二級預防中風計劃的有效性。

設計：干預前後的隊列研究比較。

安排：香港兩間普通科門診診所。

患者: 本研究包括曾於兩間診所接受長期隨訪的缺血性中風患者。其 中一間診所的中風患者接受干預（干預組），另一間診所的患者並無 接受干預（對照組）。參與者的招聘期由 2008 年9月 1 日至 2009 年2月 28日。在這6個月期間向他們收集資料, 作為干預前的數據。2009年 4月 1 日開始實施二級預防中風計劃。計劃實施9個月後（即從2010年1 月至2010年6月）開始收集患者資料作為干預後的數據, 為期6個月。

主要結果測量：干預前後的臨床資料, 包括血壓、糖化血紅蛋白、低 密度脂蛋白和處方模式。然後比較兩組數據來探討二級預防中風計劃 是否有效。

結果：研究把328名患者納入干預組, 249名患者納入對照組, 並就兩 組患者的數據資料 (干預組 256 名、對照組 210 名) 進行分析。二級預 防中風計劃實施後, 干預組在以下三方面的平均 $( \pm$ 標準差 $)$ 水平顯 著下降：收縮壓（135.2 $\pm 17.5 \mathrm{~mm} \mathrm{Hg}$ 減至 $127.7 \pm 12.2 \mathrm{~mm} \mathrm{Hg})$ 糖化血紅蛋白 $(7.2 \pm 1.0 \%$ 減至 $6.5 \pm 0.8 \%)$ 和低密度脂蛋白 $(3.4 \pm$ $0.8 \mathrm{mmol} / \mathrm{L}$ 減至 $2.8 \pm 1.3 \mathrm{mmol} / \mathrm{L})[\mathrm{P}<0.01]$ 。對照組在這三方面 並無顯著減少。兩間診所的患者在使用他汀類藥物方面明顯上升 $(\mathrm{P}<0.01)$

結論：二級預防中風計劃實施後, 普通科門診服務中缺血性中風患者 的護理得到改善。

was developed with reference to evidence-based guidelines (mainly according to the American Heart Association and American Stroke Association stroke guidelines). ${ }^{12-14}$

BOX. Clinic protocol and treatment goals of secondary stroke prevention for ischaemic stroke patients

1. Record smoking and alcohol status, with appropriate management

2. Record amount of exercise (>30-minute moderate activity), give advice

3. Record BMI: aim for $\mathrm{BMI}<23 \mathrm{~kg} / \mathrm{m}^{2}$, with management for obesity

4. Check blood pressure at each visit

- aim for $<140 / 90 \mathrm{~mm} \mathrm{Hg}$ for patients without diabetes

- aim for $<130 / 80 \mathrm{~mm} \mathrm{Hg}$ for patients with diabetes

- be aware of symptomatic hypotension

- less tight control in the presence of carotid stenosis

5. Annual blood test for fasting blood glucose and lipids

6. Patients with diabetes: aim for normoglycaemia, $\mathrm{HbA}_{1 \mathrm{c}}<7 \%$

7. Cholesterol: aim for LDL $<1.9 \mathrm{mmol} / \mathrm{L}$

- recheck lipids and liver function test after initiation of a statin

8. Antithrombotic for patients with ischaemic stroke unless contra-indicated, options:

- aspirin

- aspirin + extended-release dipyridamole

- clopidogrel

9. Warfarin for patients with atrial fibrillation unless contra-indicated

Abbreviations: $\mathrm{BMI}=$ body mass index; $\mathrm{HbA}_{\mathrm{Ic}}=$ glycated haemoglobin; $\mathrm{LDL}=$ lowdensity lipoprotein 


\section{Study design}

The target population of the study was all the ischaemic stroke patients with long-term follow-up in the two clinics. The recruitment period lasted for 6 months from 1 September 2008 to 28 February 2009. As the usual follow-up interval of long-term patients is about 3 to 4 months, the 6 -month recruitment period included all stroke patients who have regular follow-up. The pre-intervention phase data collection started within this 6-month period. The protocol implementation started at the intervention clinic on 1 April 2009. The post-intervention phase data collection started 9 months after the protocol implementation, that is, for 6 months from 1 January 2010 to 30 June 2010.

\section{Sampling}

The clinical data were collected by reviewing the medical records of all patients assigned with the International Classification of Primary Care coding of K90 (stroke/cerebrovascular accident) or K91 (cerebrovascular disease). Only those patients diagnosed with ischaemic stroke and who had at least two consecutive follow-up visits within the recruitment period were included. Patients who had a history of haemorrhagic stroke were excluded. In order to exclude patients with sporadic follow-up, only those patients with two consecutive follow-up visits in the post-intervention phase were regarded as eligible for data collection. Those patients without two consecutive follow-up visits in the postintervention phase were classified as dropouts.

\section{Protocol implementation}

One month before initiation of the protocol, two 1-hour training sessions were arranged for medical officers and nurses in the intervention clinic. During the training sessions, the treatment goals for secondary ischaemic stroke prevention and the relevant clinical evidence were presented. The workflow and applicability of the protocol were also discussed. Medical officers were required to have good documentation of all the lifestyle and cardiovascular risk factors of the ischaemic stroke patients and provide care according to the protocol. Nurses were trained to be familiar with the treatment goals and provide patient education and lifestyle modification interventions in line with the doctors' referrals. Allied health services such as a dietitian, smoking cessation clinic, diabetes complication screening programme, and patient empowerment programmes for diabetic and hypertensive patients were available in both the intervention and control clinics. Doctors in the intervention clinic were encouraged to refer appropriate patients to these services. There was no additional consultation time allocated to these patients. In order to monitor progress, the electronic consultation notes were reviewed monthly for each patient to assess compliance with the protocol. If suboptimal care was noted, an electronic reminder with appropriate management advice was issued to the patient's electronic medical record. The consulting doctor would then be able to provide the appropriate management at the next follow-up. Throughout the protocol implementation period, interim clinic meetings were held quarterly to present the data for protocol compliance with the medical and nursing staff of the intervention clinic.

In the control clinic, no specific protocol was applied. Medication prescription and adjustment was based solely on the physicians' discretion. The drug formulary was the same in both clinics. Statins were introduced to both clinic formularies in July 2009. There were no training sessions for doctors and nursing staff in the control clinic, and no electronic reminders or interim meetings for progress monitoring.

\section{Data collection}

Baseline characteristics on sex, age, chronic illness status, chronic drug use, laboratory results, and blood pressure (BP) values were extracted from the Clinical Data Analysis and Reporting System. The latest laboratory results and BP values within the data collection period were taken as the study data. Individual case records were also reviewed for the following lifestyle parameters: smoking status, alcohol consumption, body mass index (BMI), and exercise and diet history.

\section{Statistical analysis}

All statistical analysis was performed using the Statistical Package for the Social Sciences (Windows version 20.0; SPSS Inc, Chicago [IL], US). Continuous variables were expressed as mean and standard deviation. Baseline comparisons were made with the Student's $t$ test or the Chi squared test as appropriate. The mean BP, glycated haemoglobin $\left(\mathrm{HbA}_{1 \mathrm{c}}\right)$ level, and low-density lipoprotein (LDL) level before and after intervention were compared by paired-samples $t$ test in both the intervention and control clinics.

\section{Results}

In the intervention clinic, 328 patients were recruited to the intervention group and 72 dropped out. In the control clinic, 249 were recruited to the control group and 39 dropped out. The reasons for dropping out are shown in Table 1. More patients in the intervention group than in the control group dropped out due to restroke ( 9 vs 2 , respectively) and death (22 vs 11, respectively), but these were not statistically significant due to the small number of 
TABLE I. Reasons for dropping out of the study

\begin{tabular}{|c|c|c|c|}
\hline & \multicolumn{2}{|c|}{ No. (\%) } & \multirow[t]{2}{*}{ P value } \\
\hline & Intervention group & Control group & \\
\hline No. of patients in initial recruitment period & 328 & 249 & - \\
\hline No. of patients dropping out & $72(22.0)$ & $39(15.7)$ & 0.06 \\
\hline \multicolumn{4}{|l|}{ Reasons for dropping out } \\
\hline Death & $22^{*}(6.7)$ & $11 \dagger(4.4)$ & 0.24 \\
\hline Death due to stroke & $2 \ddagger(0.6)$ & $1 \S(0.4)$ & 0.73 \\
\hline Follow-up in other GOPCs & $21(6.4)$ & $13(5.2)$ & 0.55 \\
\hline Follow-up in medical clinics & $20(6.1)$ & $13(5.2)$ & 0.65 \\
\hline Due to restroke & $9 \|(2.7)$ & $29(0.8)$ & 0.09 \\
\hline Due to adverse drug effects & 0 & 0 & - \\
\hline Defaulted follow-up & $9(2.7)$ & $2(0.8)$ & 0.09 \\
\hline
\end{tabular}

Abbreviation: GOPC = general out-patient clinic

* Two patients had changes in medication during the intervention period

+ One patient had changes in medication during the intervention period

‡ Death due to stroke I month (one follow-up visit) and 4 months (two follow-up visits) after the intervention period

$\S$ Death due to stroke 5 months (one follow-up visit) after the intervention period

II Only two had restroke after the intervention period with no change in medication

T All had restroke before the intervention period

patients. In both the intervention and control groups, most of the patients who died had no medication changes during the intervention period (Table 1).

A total of 256 patients in the intervention group and 210 in the control group were recruited for data analysis. At baseline, there were no significant differences in the demographic and cardiovascular risk factor profiles between the two groups, except that patients in the intervention group had a higher mean LDL level and a lower mean diastolic BP (Table 2).

After the intervention period, significant improvements in systolic BP, $\mathrm{HbA}_{1 \mathrm{c}}$ and LDL levels were observed in the intervention group (Table 3 ). There were significant improvements in all lifestyle modification parameters (alcohol and smoking status, obtaining exercise and diet history, and BMI measurement) in the intervention group $(\mathrm{P}<0.01)$, and the control group had improvements in smoking status $(\mathrm{P}<0.01)$ and $\mathrm{BMI}$ measurement $(\mathrm{P}<0.05)$ [Table 3].

There was no significant increase in the number of antihypertensive drugs prescribed in either group (Table 4). Approximately $96 \%$ of patients were taking an antiplatelet after the intervention period in both clinics (Table 4) and the antiplatelet was always aspirin. The proportion of patients prescribed statins increased significantly in both groups since the introduction of simvastatin to the GOPC formulary in 2009. However, the overall proportion of statin use was still below $50 \%$. Statins were less frequently prescribed to patients older than 80 years (Table 5 ).

Statins were stopped for $1.6 \%$ of patients in the intervention group and $4.3 \%$ in the control group
TABLE 2. Baseline demographic data

\begin{tabular}{|c|c|c|c|}
\hline Demographics & $\begin{array}{l}\text { Intervention group } \\
\qquad(\mathrm{n}=256)^{\star}\end{array}$ & $\begin{array}{l}\text { Control group } \\
\qquad(n=210)^{\star}\end{array}$ & $P$ value \\
\hline \multicolumn{4}{|l|}{ Sex } \\
\hline Female & $140(54.7)$ & $96(45.7)$ & 0.06 \\
\hline Male & 116 (45.3) & 114 (54.3) & \\
\hline Age (years) & $73.5 \pm 9.5$ & $71.9 \pm 11.1$ & 0.31 \\
\hline Current drinker & $3(1.2)$ & $2(1.0)$ & 0.82 \\
\hline Current smoker & $25(9.8)$ & $19(9.0)$ & 0.79 \\
\hline Diabetes & $76(29.7)$ & $60(28.6)$ & 0.83 \\
\hline Atrial fibrillation & $2(0.8)$ & $3(1.4)$ & 0.5 \\
\hline Systolic BP (mm Hg) & $135.3 \pm 17.5$ & $135.6 \pm 18.4$ & 0.87 \\
\hline Diastolic BP (mm Hg) & $70.4 \pm 9.7$ & $73.5 \pm 9.2$ & $<0.01$ \\
\hline $\mathrm{HbA}_{1 \mathrm{c}}(\%)$ & $7.2 \pm 1.0$ & $7.2 \pm 1.3$ & 1 \\
\hline LDL (mmol/L) & $3.4 \pm 0.8$ & $3.0 \pm 0.8$ & $<0.01$ \\
\hline Antiplatelets & 247 (96.5) & $194(92.4)$ & 0.07 \\
\hline
\end{tabular}

Abbreviations: $\mathrm{BP}=$ blood pressure; $\mathrm{HbA}_{\mathrm{lc}}=$ glycated haemoglobin; $\mathrm{LDL}=$ low-density lipoprotein

* Data are shown as No. (\%) or mean \pm standard deviation

(Table 4). Statins were discontinued because of dyspepsia for all patients in the intervention group. The reasons for stopping statins for the control group were dyspepsia, myalgia, mild liver function derangement, hypotension, hypoglycaemia, and drug-induced hepatitis. Only two patients in the control group required emergency admission for hypoglycaemia during the intervention period. There was no restroke in the intervention group 
TABLE 3. Changes in clinical parameters and lifestyle modifications before and after the intervention

\begin{tabular}{|c|c|c|c|c|c|c|}
\hline & \multicolumn{3}{|c|}{ Intervention group $(n=256)^{*}$} & \multicolumn{3}{|c|}{ Control group $(n=210)^{*}$} \\
\hline & Pre-intervention & Post-intervention & $P$ value & Pre-intervention & Post-intervention & $P$ value \\
\hline \multicolumn{7}{|l|}{ Clinical parameter† } \\
\hline Systolic BP (mm Hg) & $135.2 \pm 17.5$ & $127.7 \pm 12.2$ & $<0.01$ & $135.7 \pm 18.4$ & $134.5 \pm 16.9$ & 0.49 \\
\hline Diastolic BP (mm Hg) & $70.4 \pm 9.7$ & $68.1 \pm 9.3$ & $<0.01$ & $73.5 \pm 9.2$ & $72.1 \pm 10.6$ & 0.04 \\
\hline $\mathrm{HbA}_{1 \mathrm{c}}(\%)$ & $7.2 \pm 1.0$ & $6.5 \pm 0.8$ & $<0.01$ & $7.2 \pm 1.3$ & $6.9 \pm 0.8$ & 0.13 \\
\hline $\mathrm{LDL}(\mathrm{mmol} / \mathrm{L})$ & $3.4 \pm 0.8$ & $2.8 \pm 1.3$ & $<0.01$ & $3.0 \pm 0.8$ & $3.0 \pm 0.7$ & 0.36 \\
\hline BMI $\left(\mathrm{kg} / \mathrm{m}^{2}\right)$ & - & $24.0 \pm 3.6$ & & - & $25.5 \pm 4.1$ & \\
\hline \multicolumn{7}{|l|}{ Alcohol consumption } \\
\hline Unknown & $179(69.9)$ & $16(6.3)$ & $<0.01$ & $165(78.6)$ & $160(76.2)$ & 0.85 \\
\hline Non-drinker & $62(24.2)$ & 225 (87.9) & & $35(16.7)$ & $40(19.0)$ & \\
\hline Current drinker & $3(1.2)$ & 0 & & $2(1.0)$ & $1(0.5)$ & \\
\hline Ex-drinker & $12(4.7)$ & $15(5.9)$ & & $8(3.8)$ & $9(4.3)$ & \\
\hline \multicolumn{7}{|l|}{ Smoking status } \\
\hline Unknown & $111(43.4)$ & $1(0.4)$ & $<0.01$ & $59(28.1)$ & $19(9.0)$ & $<0.01$ \\
\hline Non-smoker & $84(32.8)$ & $187(73.0)$ & & $83(39.5)$ & $117(55.7)$ & \\
\hline Current smoker & $25(9.8)$ & $20(7.8)$ & & $19(9.0)$ & $17(8.1)$ & \\
\hline Ex-smoker & $36(14.1)$ & $48(18.8)$ & & $49(23.3)$ & $57(27.1)$ & \\
\hline \multicolumn{7}{|l|}{ Diet } \\
\hline Diet history obtained & $52(20.3)$ & $238(93.0)$ & $<0.01$ & $91(43.3)$ & $68(32.4)$ & 0.02 \\
\hline No diet history & $204(79.7)$ & $18(7.0)$ & & $119(56.7)$ & $142(67.6)$ & \\
\hline \multicolumn{7}{|l|}{ Exercise } \\
\hline Exercise history obtained & $62(24.2)$ & 237 (92.6) & $<0.01$ & $54(25.7)$ & $64(30.5)$ & 0.62 \\
\hline No exercise history & $194(75.8)$ & $19(7.4)$ & & $156(74.3)$ & $166(79.0)$ & \\
\hline \multicolumn{7}{|l|}{ BMI } \\
\hline BMI measured & $11(4.3)$ & 203 (79.3) & $<0.01$ & 0 & $40(19.0)$ & $<0.01$ \\
\hline No BMI measured & $245(95.7)$ & $53(20.7)$ & & $210(100)$ & $170(81.0)$ & \\
\hline
\end{tabular}

Abbreviations: $\mathrm{BMI}=$ body mass index; $\mathrm{BP}=$ blood pressure; $\mathrm{HbA}_{\mathrm{lc}}=$ glycated haemoglobin; $\mathrm{LDL}=$ low-density lipoprotein

* Data are shown as mean \pm standard deviation, or No. (\%)

† The last values were recorded for patients who had more than one measurement during the intervention phase

$\ddagger$ Pre-intervention BMI record rate too low for comparison

and four restrokes in the control group during the intervention period.

\section{Discussion}

This study showed that the implementation of a secondary stroke prevention programme in GOPCs could improve control of cardiovascular risk factors, including $\mathrm{BP}, \mathrm{HbA}_{1 \mathrm{c}}$ and LDL levels among ischaemic stroke patients. We observed an improvement of $\mathrm{BP}$ control in the intervention group, although there was no significant increase in the number of antihypertensives used. However, since simvastatin was introduced into the GOPC drug formulary in 2009 , the use of statins increased in both the control and intervention clinics, although the effect of LDL reduction was only observed in the intervention group. This result implies that the improvement in outcome for this group is due to more than just the effects of medications. Lifestyle modifications may provide additional benefits.

Although the $\mathrm{BP}$ and $\mathrm{HbA}_{1 \mathrm{c}}$ level in the intervention group were comparable with recent recommendations ( $\mathrm{BP}<140 / 90 \mathrm{~mm} \mathrm{Hg}$ for patients without diabetes; $\mathrm{BP}<130 / 80 \mathrm{~mm} \mathrm{Hg}$ and $\mathrm{HbA}_{1 \mathrm{c}}$ level of $<7 \%$ for patients with diabetes), the mean LDL levels remained well above the recommended target of $1.9 \mathrm{mmol} / \mathrm{L}$. Only about half of the patients were taking statins. There is a suggestion that doctors may not prescribe or maximise statin therapy because treatment may be considered futile, especially among older people whose life expectancy is limited. ${ }^{15}$ This trend was observed in both the control and intervention sites in this study (Table 4). The percentage of patients taking statins was relatively low in this study as some doctors may have 
TABLE 4. Comparison of medication use between the intervention and control groups

\begin{tabular}{|c|c|c|c|c|}
\hline & \multicolumn{4}{|c|}{$\%$} \\
\hline & \multicolumn{2}{|c|}{ Intervention group $(n=256)$} & \multicolumn{2}{|c|}{ Control group $(n=210)$} \\
\hline & Pre-intervention & Post-intervention & Pre-intervention & Post-intervention \\
\hline \multicolumn{5}{|l|}{ No. of antihypertensive drugs } \\
\hline 0 & 15.2 & 12.9 & 18.6 & 14.8 \\
\hline 1 & 44.1 & 39.5 & 30.5 & 33.8 \\
\hline 2 & 30.9 & 35.9 & 35.7 & 32.4 \\
\hline 3 & 9.0 & 9.8 & 12.4 & 14.8 \\
\hline 4 & 0.8 & 2.0 & 1.4 & 3.8 \\
\hline 5 & 0.0 & 0.0 & 1.4 & 0.5 \\
\hline Mean No. of antihypertensive drugs & 1.4 & 1.5 & 1.5 & 1.6 \\
\hline Proportion taking statins & 17.2 & $41.8^{*}$ & 21.4 & $36.2^{*}$ \\
\hline \multicolumn{5}{|l|}{ Change in statin use } \\
\hline Statin stopped & \multicolumn{2}{|c|}{1.6} & \multicolumn{2}{|c|}{4.3} \\
\hline No change & \multicolumn{2}{|c|}{72.3} & \multicolumn{2}{|c|}{76.7} \\
\hline Statin initiated & \multicolumn{2}{|c|}{26.2} & \multicolumn{2}{|c|}{19.0} \\
\hline Proportion taking antiplatelets & 95.3 & 96.9 & 91.9 & 96.2 \\
\hline
\end{tabular}

* Significant difference between pre- and post-intervention data in both groups, $\mathrm{P}<0.01$

concerns about the possible side-effects. However, no severe adverse effects of statins were noted in the intervention group despite the more aggressive treatment approach.

The implementation of secondary stroke prevention protocol has raised doctors' awareness of lifestyle modification for patients with ischaemic stroke. This was reflected by the significant increase in the use of lifestyle modifications in the intervention group. We encouraged doctors to provide appropriate advice on lifestyle modification when lifestyle risk factors were identified during the consultation. However, due to heavy patient loads in the GOPC, no additional time can be allocated for medical consultations. During clinic meetings, our staff expressed difficulty in providing quality lifestyle education due to limited consultation time. The lack of additional resources for lifestyle education was a main shortcoming of this programme.

Certain subgroups of ischaemic stroke patients are not well represented by this study, for example, those with atrial fibrillation. Atrial fibrillation is one of the major risk factors for recurrent stroke. ${ }^{16}$ However, as warfarin was not available in the drug formulary of the GOPCs during the study period, most patients with atrial fibrillation were not referred to these clinics. Only a few patients with atrial fibrillation were identified in our study and all of them had a contra-indication for warfarin. At the time of writing, warfarin has become available in the GOPCs and several novel anticoagulants have been introduced as self-finance items. The use of anticoagulants in GOPCs is an important aspect of
TABLE 5. Statin usage stratified according to age-group

\begin{tabular}{lccc}
\hline \multirow{2}{*}{$\begin{array}{l}\text { Age-group } \\
\text { (years) }\end{array}$} & \multicolumn{2}{c}{ No. (\%) } & P value \\
\cline { 2 - 3 } & Intervention group (n=256) & Control group (n=210) & \\
\hline$\leq 60$ & $13 / 29(44.8)$ & $12 / 37(32.4)$ & 0.32 \\
\hline $61-70$ & $36 / 70(51.4)$ & $24 / 46(52.2)$ & 1 \\
$71-80$ & $42 / 97(43.3)$ & $28 / 81(34.6)$ & 0.28 \\
$\geq 81$ & $16 / 60(26.7)$ & $12 / 46(26.1)$ & 1 \\
\hline
\end{tabular}

secondary stroke prevention that warrants further investigation.

Implementation of evidence-based guidelines into routine clinical practice is complicated. ${ }^{17,18}$ Physicians usually have concerns about the applicability of new trial data to individual patients, and it takes time for them to change their practice. Apart from considering the best available evidence, we also need to take into account the practical barriers in the clinical practice setting. The heavy workload in the clinic, shortage of consultation time, and limited scope of the drug formulary may impose difficulty in introducing an evidence-based protocol to local GOPCs.

From the experience of this study, a dedicated training session for clinic staff is necessary before the implementation of any new protocol. Additional review sessions are needed to audit clinicians' compliance with the protocol. Review of the GOPC drug formulary, for example, to include 
greater choices of statins and antiplatelets, may be helpful to improve the care of stroke patients. Lifestyle modification is an important aspect for secondary stroke prevention, but time constraints in busy GOPCs are always an issue. A designated nurse clinic for patient education and annual risk factor monitoring should be introduced. For better utilisation of resources, it is beneficial to recruit community partners from allied health services to provide a structured secondary stroke prevention programme for patient empowerment and engagement.

In our study, approximately $5 \%$ to $6 \%$ of patients were lost to other GOPCs and medical clinics (Table 1). This may introduce some bias. In addition, differences between the two clinics such as proportions of health care workers, doctors' qualifications, and differences in the socio-economic groups of the patients are possible confounders that might introduce bias. The intervention group had a higher rate of dropouts due to death and restroke although this was not statistically significant. As most of these patients had no change in medications during the intervention period (Table 1), the higher death and restroke rates were unlikely to be related to any adverse effects from the implementation of the protocol. However, we do not have data on the rates of stroke recurrence, adverse events, and mortality over a longer period, which are the most important outcomes for effective secondary stroke prevention. Furthermore, we may need to take into account the Hawthorne effect when looking at the effectiveness of the protocol implementation, in that physicians perform better simply because they are aware that they are in a study rather than because of the nature of the protocol. ${ }^{19,20}$ This is an unavoidable bias in clinical research.

\section{Conclusion}

This study demonstrates that through implementation of a standardised treatment protocol, the standard of care of secondary stroke prevention for ischaemic stroke patients could be improved in local GOPCs. However, due to the relatively small sample size in this study, this preliminary result should be interpreted with caution and further studies involving more primary care clinics are required to test its clinical value.

\section{References}

1. The top ten causes of death. (Fact sheet No 310/July 2013). Geneva: World Health Organization; 2013.

2. Centre for Health Protection. Vital statistics: death rates by leading causes of death, 2001-2012. Hong Kong: HKSAR Government.

3. Centre for Health Protection. Health topics: non communicable diseases and risk factors: cerebrovascular disease. Available from: http://www.chp.gov.hk/en/ content/9/25/58.html. Accessed 31 Mar 2014.

4. Cheung CM, Tsoi TH, Hon SF, et al. Outcomes after firstever stroke. Hong Kong Med J 2007;13:95-9.

5. Tsoi TH, Huang CY, Hon SF, et al. Trends in stroke types and mortality in Chinese. Stroke 2004;35:e256.

6. Wong $\mathrm{HC}$, Mok CT. Update on secondary stroke prevention. Hong Kong Pract 2007;29:271-6.

7. Wang Y, Wu D, Wang Y, Ma R, Wang C, Zhao W. A survey on adherence to secondary ischemic stroke prevention. Neurol Res 2006;28:16-20.

8. Whitford DL, Hickey A, Horgan F, O'Sullivan B, McGee H, O'Neill D. Is primary care a neglected piece of the jigsaw in ensuring optimal stroke care? Results of a national study. BMC Fam Pract 2009;10:27.

9. Ovbiagele B, Drogan O, Koroshetz WJ, Fayad P, Saver JL. Outpatient practice patterns after stroke hospitalization among neurologists. Stroke 2008;39:1850-4.

10. Rudd AG, Lowe D, Hoffman A, Irwin P, Pearson M. Secondary prevention for stroke in the United Kingdom: results from the National Sentinel Audit of Stroke. Age Ageing 2004;33:280-6.

11. Xu G, Liu X, Wu W, Zhang R, Yin Q. Recurrence after ischemic stroke in Chinese patients: impact of uncontrolled modifiable risk factors. Cerebrovasc Dis 2007;23(2-3):11720.

12. Sacco RL, Adams R, Albers G, et al. Guidelines for prevention of stroke in patients with ischemic stroke or transient ischemic attack: a statement for healthcare professionals from the American Heart Association/ American Stroke Association Council on Stroke: cosponsored by the Council on Cardiovascular Radiology and Intervention: the American Academy of Neurology affirms the value of this guideline. Stroke 2006;37:577-617.

13. Adams RJ, Albers G, Alberts MJ, et al. Update to the AHA/ ASA recommendations for the prevention of stroke in patients with stroke and transient ischemic attack. Stroke 2008;39:1647-52.

14. Furie KL, Kasner SE, Adams RJ, et al. Guidelines for the prevention of stroke in patients with stroke or transient ischemic attack: a guideline for healthcare professionals from the American Heart Association/American Stroke Association. Stroke 2011;42:227-76.

15. Walker DB, Jacobson TA. Initiating statins in the elderly: the evolving challenge. Curr Opin Endocrinol Diabetes Obes 2008;15:182-7.

16. Li R, Cheng S, Mok $\mathrm{M}$, et al. Atrial fibrillation is an independent risk factor of poor stroke outcome and mortality in Chinese ischaemic stroke patients. Cerebrovasc Dis 2013;36(Supp 1):74.

17. Cranney M, Warren E, Barton S, Gardner K, Walley T. Why do GPs not implement evidence-based guidelines? A descriptive study. Fam Pract 2001;18:359-63.

18. Foy R, Eccles M, Grimshaw J. Why does primary care need more implementation research? Fam Pract 2001;18:353-5.

19. Wickström G, Bendix T. The "Hawthorne effect"-what did the original Hawthorne studies actually show? Scand J Work Environ Health 2000;26:363-7.

20. McCarney R, Warner J, Iliffe S, van Haselen R, Griffin M, Fisher P. The Hawthorne effect: a randomised, controlled trial. BMC Med Res Methodol 2007;7:30. 